\title{
Optimization of Processing Technology of Compound Dandelion Wine
}

\author{
Jixuan $\mathrm{Wu}^{1}$, Guangren Sun ${ }^{1, \mathrm{a}}$, Xiuli $\mathrm{CaO}^{1}$, Yuting $\mathrm{Han}^{1}$, Xuesong Sun ${ }^{1}$, Huan Zhang ${ }^{1}$, Lei Zhang ${ }^{1}$, and Ataer Dang ${ }^{1}$ \\ ${ }^{1}$ Department of Food Science \& Engineering, Beihua University, 3999 Binjiang East RD, 132013, Jilin, China
}

\begin{abstract}
Exploring dandelion food has been the concern in fields of the food processing and pharmaceutical industry for playing exact curative effect on high-fat-diet induced hepatic steatosis and diuretic activity. Few dandelion foods including drinks and microencapsulation were explored and unilateral dandelion wine were less carried out for its bitter flavour. In tis paper, to optimize the processing technologies of fermented compound wine from dandelion root, the orthogonal experiment design method was used to composite dandelion root powder with glutinous rice and schisandra fruit and optimize the fermenting parameters. Four factors with dandelion content, schisandra content, acidity and sugar content were discussed. The acidity factor was firstly confirmed as $7.0 \mathrm{~g} / \mathrm{L}$. The other three factors were confirmed by a series experiments as dandelion $0.55 \%$, schisandra $0.5 \%$, sugar $22 \%$. With nine step processing of mixing substrate, stirring with water, cooking rice, amylase saccharification, pectinase hydrolysis, adjusting juice, fermenting with yeast, fitering, aging, sterilization, a light yellow wine with the special taste with flavour of dandelion, schisandra and rice and less bitter, few index were determined as $14.7 \%$ alcohol , 6.85 $\mathrm{g} / \mathrm{L}$ acidity. A dandelion fermented compound wine with suitable flavour and sanitarian function was developed for enriching the dandelion food.
\end{abstract}

\section{Introduction}

Dandelion (Taraxacum officinale Weber ex Wigg.) is a perennial weed widely distributed in the warmer temperate zones of the Northern Hemisphere [1]. This herb has been known since ancient times for its curative properties and has been utilized for the treatment of various ailments as a traditional medicine in China. Dandelion have long been used as medicinal herbs and young leaves are consumed fresh in salad, whereas roots are roasted and utilized as a coffee substitute and the plant extracts are used as flavor components in various food products. In China, this herbal plant used as both herbal medicine and edible vegetable [2].

Many active components were identified in dandelion including sesquiterpene lactones, taraxacoside, triterpenes, phytosterols, phenolic acids, flavonoids, polysaccharide, proline-hydroxyproline glycopeptides, vitamins, minerals and volatile components [3-7]. Dandelion has some activities and can be used medicine and food [8-11]. Its activities include protect effect on high-fat-diet induced hepatic steatosis, estrogenic activity, diuretic activity, choleretic activity, anti-inflammatory activity, antioxidative activity, anti-carcinogenic activity, analgesic activity, anti-allergic activity, anti-hyperglycemic activity, prebiotic activity, anti-coagulatory, anti-thrombotic activity, Empiric traditional application in humans of dandelion, in particular to treat digestive disorders.

For these activities, this herb is also used as food, including emulsion templated microencapsulation of dandelion, special drinks such as coffee from dandelion

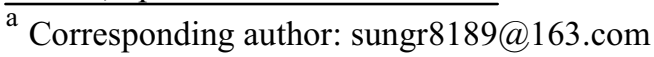

flower, green vegetable from tender dandelion leaves, functional products from dandelion root. But there is less research on wine from dandelion root especially less on fermented compound wine from dandelion root. In this paper, the technologies of processing on fermented compound wine from dandelion root were discussed for further filling lists of the food products from dandelion.

\section{Materials and Methods}

\subsection{Materials}

Dandelion (T. officinale) root were collected from Jiaohe city of Jilin, China in September to October, 2014. These root were washed by running water and dried in shade, then smashed by screen mesh with $250 \mu \mathrm{m}$ mesh. Schisandra (Schisandra chinensis) fruit were collected from Jian city of Jlin, China in September, 2014. The fresh fruit of schisandra were dried and stored in a cool, ventilated place. The glutinous rice, saccharifying enzyme and active dry yeast was purchased from Jilin market, China, in January, 2015.

\subsection{Methods}

Fermentation processes included four steps. Firstly, making the composite powder as fermentation substrate mixed by dandelion powder with dried schisandra fruit and glutinous rice. Secondly, cooking the composite 
powder after added certain amount of water. Thirdly, adjusting fermentation substrate contained 5 times water, acidity with $7.0 \mathrm{~g} / \mathrm{L}$ by citric acid, sugar content with $24 \%$ by white granulated sugar. Lastly, incubating yeast with $0.01 \%$ and fermented for five to seven days under the condition of temperature between $21^{\circ} \mathrm{C}$ and $28^{\circ} \mathrm{C}$.

The methods of determination of sugar, acidity and alcohol. Sugar determined by the method of REDOX titration, acidity (calculated by citric acid as $\mathrm{g} / \mathrm{L}$ ) by acidalkali neutralization titration, alcohol by wine viscometer method.

The methods of composite substrate by experiment designs including single factor experiments design and orthogonal experiment design. Factors included the ratio of content of dandelion powder, content of acidity, content of sugar and content of schisandra. Content of dandelion changed as $0.5 \%, 0.6 \%, 0.7 \%, 0.8 \%, 0.9 \%$, $1.0 \%$ schisandra as $0.5 \%, 0.6 \%, 0.7 \%, 0.8 \%, 0.9 \%, 1.0 \%$, sugar as $16 \%, 18 \%, 20 \%, 22 \%, 24 \%, 26 \%$, acidity as 5.5 $\mathrm{g} / \mathrm{L}, 6.0 \mathrm{~g} / \mathrm{L}, 6.5 \mathrm{~g} / \mathrm{L}, 7.0 \mathrm{~g} / \mathrm{L}, 7.5 \mathrm{~g} / \mathrm{L}, 8.0 \mathrm{~g} / \mathrm{L}$. The single experiments were evaluated by alcohol yields, residue sugar and sensory evaluation and appropriate range of these factors were determined. Based on these test, three main factors with appropriate range were selected. Three factors and three levels were used in orthogonal test design as $\mathrm{L}_{9}\left(3^{4}\right)$. Finally, validation experiments were designed for further composite level and gained optimal conditions.

The processing of compound wine included mixing substrate, stirring with water, cooking rice, enzymatic saccharification with amylase, pectinase hydrolysis, adjusting acidity, adding sugar, fermenting with wine active dry yeast, filtering, wine aging, sterilization.

\section{Experiment Results and Discussion}

\subsection{Results of single factor experiment}

The results of single factor experiments described the effect of dandelion and schisandra was showed in the Figure 1.

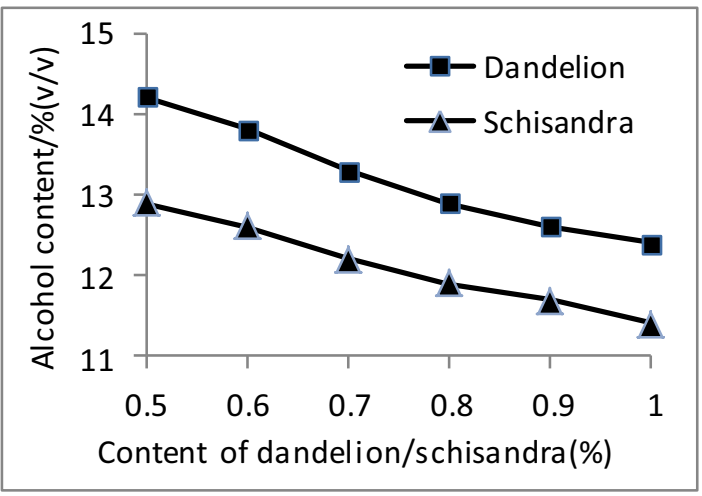

Figure 1. Effects of dandelion and schisandra on alcohol.

From Figure 1, the rules showed that the fermented alcohol gradually reduced with the increase of the substrate concentration both in schisandra on alcohol. This showed the dandelion and schisandrae had a negative effect on alcoholic fermentation and more strong effect of schisandra than dandelion. For further orthogonal test design the three levels of $0.6 \%, 0.7 \%$ and $0.8 \%$ were selected in with considering the sensory evaluation.

The results of single factor experiment of acidity and sugar content were showed in Table 1 and Table 2.

From Table 1, the alcohol content increased with the increase of sugar content when the sugar content changed between $16 \%$ and $22 \%$, but over $22 \%$, the alcohol increased in not obvious level. For further orthogonal test design the three levels of $20 \%, 22 \%$ and $24 \%$ were selected.

From Table 2, the alcohol content increased with the increase of acidity when the acidity more than $7.0 \mathrm{~g} / \mathrm{L}$, but acidity changed between $5.5 \mathrm{~g} / \mathrm{L}$ and $7.0 \mathrm{~g} / \mathrm{L}$, the alcohol changed in not obvious level. So, select the acidity level between $5.0 \mathrm{~g} / \mathrm{L}$ and $7.0 \mathrm{~g} / \mathrm{L}$. For the further test the acidity of $7.0 \mathrm{~g} / \mathrm{L}$ was determined to keep high acidity for preventing bacterial contamination.

Table 1. The effects of sugar content on alcohol

\begin{tabular}{|c|c|c|}
\hline No. & $\begin{array}{c}\text { Sugar Content } \\
\mathbf{\%}(\mathbf{m} / \mathbf{m})\end{array}$ & $\begin{array}{c}\text { Alcohol } \\
\mathbf{\%}(\mathbf{v} / \mathbf{v})\end{array}$ \\
\hline 1 & 16 & 12.8 \\
\hline 2 & 18 & 13.2 \\
\hline 3 & 20 & 14.5 \\
\hline 4 & 22 & 14.8 \\
\hline 5 & 24 & 14.7 \\
\hline 6 & 26 & 14.6 \\
\hline
\end{tabular}

Table 2. The effects of acidity on alcohol

\begin{tabular}{|c|c|c|}
\hline No. & $\begin{array}{c}\text { Acidity } \\
\text { g/L }\end{array}$ & $\begin{array}{c}\text { Alcohol } \\
\mathbf{\%}(\mathbf{v} / \mathbf{v})\end{array}$ \\
\hline 1 & 5.5 & 14.6 \\
\hline 2 & 6.0 & 14.5 \\
\hline 3 & 6.5 & 14.2 \\
\hline 4 & 7.0 & 14.5 \\
\hline 5 & 7.5 & 13.8 \\
\hline 6 & 8.0 & 12.6 \\
\hline
\end{tabular}

\subsection{Results of orthogonal test}

To set up orthogonal test design, the factor-level table was determined in Table 3 . The results of this design was showed in Table 4.

Table 3. The factor-level table of substrate composite

\begin{tabular}{|c|c|c|c|}
\hline \multirow{3}{*}{ Levelss } & \multicolumn{3}{|c|}{ Factors } \\
\cline { 2 - 4 } & $\begin{array}{c}\mathbf{A} \\
\text { Dandelion } \\
\mathbf{\%}\end{array}$ & $\begin{array}{c}\text { B } \\
\text { Sugar } \\
\mathbf{\%}\end{array}$ & $\begin{array}{c}\mathbf{C} \\
\text { Schisandra } \\
\mathbf{\%}\end{array}$ \\
\hline 1 & 0.5 & 20 & 0.5 \\
\hline 2 & 0.6 & 22 & 0.6 \\
\hline 3 & 0.7 & 24 & 0.7 \\
\hline
\end{tabular}

Table 4 showed that the factor $\mathrm{A}$ had the biggest range and the factor lower than $\mathrm{A}$, that to say the factor $\mathrm{A}$ (dandelion content) is the main factor to fermentation.

Table 5 showed the variance analysis of this test, the results showed that the factor $\mathrm{A}$ had a significant difference. This conclusion was the same as Table 4. But 
the factor $\mathrm{C}$ (schisandra content) had low level to improve the taste.

Table 4. The analysis results of orthogonal test

\begin{tabular}{|c|c|c|c|c|c|}
\hline No & A & B & C & D & Scores \\
\hline 1 & 1 & 1 & 1 & 1 & 75.7 \\
\hline 2 & 1 & 2 & 2 & 2 & 77.4 \\
\hline 3 & 1 & 3 & 3 & 3 & 70.2 \\
\hline 4 & 2 & 1 & 2 & 3 & 87 \\
\hline 5 & 2 & 2 & 3 & 1 & 85.6 \\
\hline 6 & 2 & 3 & 1 & 2 & 90.6 \\
\hline 7 & 3 & 1 & 3 & 2 & 75.6 \\
\hline 8 & 3 & 2 & 1 & 3 & 80.8 \\
\hline 9 & 3 & 3 & 2 & 1 & 78.2 \\
\hline K1 & 223.3 & 238.3 & 247.1 & 239.5 & \\
\hline K2 & 263.2 & 243.8 & 242.6 & 243.6 & \\
\hline K3 & 234.6 & 239.0 & 231.4 & 238.0 & \\
\hline k1 & 74.43 & 79.43 & 82.37 & 79.83 & \\
\hline k2 & 87.73 & 81.27 & 80.87 & 81.20 & \\
\hline k3 & 78.20 & 79.67 & 77.13 & 79.33 & \\
\hline R & 13.30 & 1.83 & 5.23 & 1.87 & \\
\hline
\end{tabular}

Table 5. Analysis table of variance on orthogonal test

\begin{tabular}{|c|c|c|c|c|}
\hline Source & Sum & DF & Variance & F value \\
\hline A & 281.96 & 2 & 140.98 & $50.33^{*}$ \\
\hline B & 5.98 & 2 & 2.99 & 1.07 \\
\hline C & 43.58 & 2 & 21.79 & 7.78 \\
\hline Error & 5.60 & 2 & 2.801 & \\
\hline \multicolumn{5}{|c|}{ Note: ${ }^{*} \mathrm{~F}_{0.05}=19$, significant }
\end{tabular}

From the above analysis, factor A was the most major in the three factors and this factor should be further determined by single factor test.

In above analysis the most combination of these factors is $\mathrm{A}_{2} \mathrm{~B}_{2} \mathrm{C}_{1}$, that is, dandelion content as $0.6 \%$, sugar content as $22 \%$ and schisandra content as $0.5 \%$.

\subsection{Results of further single factor test}

To determine the best range of dandelion content, a further single factor test was used in Table 6 with sugar content as $22 \%$ and schisandra content as $0.5 \%$ the results were evaluated by taste evaluation.

Table 6. The effects of dandelion content on taste and alcohol

\begin{tabular}{|c|c|c|c|}
\hline No. & $\begin{array}{c}\text { Dandelion } \\
\text { Content } \\
\mathbf{\%}(\mathbf{m} / \mathbf{m})\end{array}$ & $\begin{array}{c}\text { Alcohol } \\
\mathbf{\%}(\mathbf{v} / \mathbf{v})\end{array}$ & $\begin{array}{c}\text { Taste } \\
\text { Scores }\end{array}$ \\
\hline 1 & 0.45 & 14.8 & 89.7 \\
\hline 2 & 0.50 & 14.2 & 90.5 \\
\hline 3 & 0.55 & 14.5 & 92.1 \\
\hline 4 & 0.60 & 14.8 & 90.1 \\
\hline 5 & 0.65 & 14.7 & 89.7 \\
\hline 6 & 0.70 & 14.6 & 84.3 \\
\hline
\end{tabular}

From Table 6, the alcohol content had nor obviously significant difference, but the taste scores had obviously significant difference. The biggest dandelion content was about $0.55 \%$.

\subsection{Results of verification experiment}

To determine the best fermentation condition and best range of substrate content, a verification experiment was worked out in Table 7, the results were evaluated by taste evaluation and the analysis table of variance on verification experiment were showed in Table 8.

Table 7. The results of verification experiment

\begin{tabular}{|c|c|c|c|c|}
\hline Method & $\mathrm{A}(\%)$ & $\mathrm{B}(\%)$ & $\mathrm{C}(\%)$ & Scores* $^{*}$ \\
\hline 1 & 0.55 & 22 & 0.5 & $92.2 \pm 0.3^{\mathrm{a}}$ \\
\hline 2 & 0.6 & 22 & 0.5 & $90.8 \pm 0.7^{\mathrm{a}}$ \\
\hline 3 & 0.6 & 24 & 0.5 & $91.1 \pm 0.7^{\mathrm{a}}$ \\
\hline 4 & 0.5 & 20 & 0.5 & $76.2 \pm 1.1^{\mathrm{c}}$ \\
\hline 5 & 0.7 & 24 & 0.7 & $82.4 \pm 0.7^{\mathrm{b}}$ \\
\hline
\end{tabular}

Table 8. Analysis table of variance on verification experiment

\begin{tabular}{|c|c|c|c|c|}
\hline Source & Sum & DF & Variance & F value \\
\hline Method & 783.36 & 4 & 195.8 & $353.5^{* *}$ \\
\hline Error & 8.31 & 15 & 0.554 & \\
\hline Total & 791.67 & 19 & & \\
\hline \multicolumn{5}{|c|}{ Note: Repeat $\mathrm{n}=3, \mathrm{~F}_{0.01}(4,15)=4.89$} \\
\end{tabular}

In verification test, choose the best in further single factor test as method 1, best in orthogonal test as method 2 , results of orthogonal test as method 3 , the lowest level as method 4 and the highest level as method 5 .

From Table 8, these methods have obviously significant difference, and the multiple comparison method can be used in Table 7. By the analysis of multiple comparison method, method 1, method 2 and method 3 were not significant but significant to method 4 and 5 .

\subsection{Optimization of composite substrate}

From above discussion, four factors with dandelion content, schisandra content, acidity and sugar content were discussed. The acidity factor was firstly confirmed as $7.0 \mathrm{~g} / \mathrm{L}$. The other three factors were confirmed by a series experiments as dandelion $0.55 \%$, schisandra $0.5 \%$, sugar $22 \%$.

In order to facilitate application of optimized formula, reorganize the making process of the fermentation substrate are listed in Table 9.

Table 9. The list of substrate formula

\begin{tabular}{|c|c|c|c|}
\hline Material & State & Content & $\begin{array}{c}\text { Amount } \\
\mathrm{kg} / \mathrm{t}\end{array}$ \\
\hline Dandelion & $\begin{array}{c}\text { Dried root } \\
\text { powder }\end{array}$ & $0.55 \%$ & 5.5 \\
\hline Schisandra & $\begin{array}{c}\text { Dried fruit } \\
\text { powder }\end{array}$ & $0.50 \%$ & 5.0 \\
\hline Glutinous rice & powder & $10 \%$ & 100 \\
\hline Sugar & powder & $22 \%$ & 220 \\
\hline $\mathrm{SO}_{2}$ & $6.0 \%$ liquid & $120 \mathrm{mg} / \mathrm{L}$ & 2.0 \\
\hline $\mathrm{Citric}$ acid & powder & $7.0 \mathrm{~g} / \mathrm{L}$ & 7.0 \\
\hline Water & Liquid & & 662.5 \\
\hline Total & & & 1000 \\
\hline
\end{tabular}


Based above tests, the substrate formula of compound wine was determined, and the processing technologies were determined according to these experiments. The compound wine processing included four steps.

Step 1: Mixing substrate - Powder of dried dandelion root, dried schisandra fruit and rice powder were mixed as composite substrate.

Step 2: Stirring with water - Above composite substrate was stirred with water at 3 times of powder as composite juice.

Step 3: Cooking rice - Above composite juice was cooked at $121^{\circ} \mathrm{C}$ for $30 \mathrm{~min}$ as cooked juice.

Step 4: Enzymatic saccharification with amylase Above cooked juice cooled about $60{ }^{\circ} \mathrm{C}$ and keep this temperature for $2 \mathrm{hr}$, , adding amylase to make the starch from dandelion and rice change to sugar as saccharification juice.

Step 5: Pectinase hydrolysis - Keep saccharification juice at $50^{\circ} \mathrm{C}$, adding pectinase for $5 \mathrm{hr}$. as purification juice.

Step 6: Adjusting juice - adjusting $7.0 \mathrm{~g} / \mathrm{L}$ acidity with citric acid, $22 \%$ sugar with white granulated sugar, $120 \mathrm{mg} / \mathrm{L} \quad \mathrm{SO}_{2}$ with $6.0 \%$ sulfurous acid solution as adjusted juice

Step 7: Fermenting with wine active dry yeast Adding wine active dry yeast after activated to adjusted juice and fermented for five to seven days with stirring every day. When there is less gas in the fermentation, the main fermentation had a stop and the fermentation would go into after fermentation. First fermented juice was obtained by the main fermentation.

Step 8: Filtering, wine aging - In this transition process of first fermented juice to after fermentation, the filtering operation is necessary to prevent bacteria pollution. After filtering, the fermenting process change into wine aging for three to five months as fermented juice.

Step 9, Sterilization - Above fermented juice should be operated with sterilization by high temperature instantaneous fungicide in $135^{\circ} \mathrm{C}$ for $3-5 \mathrm{~S}$.

Some components were determined as $14.7 \%$ alcohol, $6.85 \mathrm{~g} / \mathrm{L}$ acidity (calculated by citric acid), $0.67 \%$ residue sugar.

\subsection{Further exploration on dandelion wine}

Processing of fermented wine processing traditionally contains material treating, fermenting by yeast, and wine aging. And in this paper, the processing of fermented dandelion wine included material treating, material composing, enzyme hydrolysis, fermenting by yeast and wine aging [12]. The difference between above processes is filling material composing and enzyme hydrolysis as special two steps from dandelion wine. This innovation improved the flavour of fermented dandelion wine.

Fermentation using microorganismreactor synthesis natural on dandelion can improve product chlorogenic acid possibility and flavour [13]. In this paper, the fermentation technologies included enzyme and yeast, the flavour was improved, if there is any improving components in the fermenting process should be further studied.

\section{Conclusion}

Processing technologies of fermented dandelion wine were optimized by single factor experiment and orthogonal test design. Among four factors affecting compound wine, the acidity factor was firstly confirmed as $7.0 \mathrm{~g} / \mathrm{L}$. The other three factors were confirmed by a series experiments as dandelion $0.55 \%$, schisandra $0.5 \%$, sugar $22 \%$. Through nine-step processing of mixing substrate, stirring with water, cooking rice, amylase saccharification, pectinase hydrolysis, adjusting juice, fermenting with yeast, fitering, aging and sterilization, a light yellow wine with the special taste with flavour of dandelion, schisandra and rice and less bitter. Some index were determined as $14.7 \%$ alcohol, $6.85 \mathrm{~g} / \mathrm{L}$ acidity (calculated by citric acid), $0.67 \%$ residue sugar.

Bitter taste from the fermented dandelion wine was solved by composite technology. Unilateral dandelion wine were less carried out for its bitter flavour. Although fermented dandelion root was less bitter than un fermented, but the bitter taste was still unpleasant. To solve this problem, schisandra fruit with high level acidity content was selected to improve acid content. Based on compositing dandelion with schisandra, sugar was another high sugar level seasoning. To develop the compound fermented wine, glutinous rice was used as a sugar substrate through the fermented method by enzyme. By above measures, the bitter taste of fermented wine from dandelion root was developed.

Dandelion food was compositing with schisandra to strengthen the effect on protecting liver function. Schisandra has strong antioxidant activities and significant protective effect against acute hepatotoxicity induced by $\mathrm{CCl}_{4}$. The effect on protecting liver function of dandelion wine had been on protecting liver functioned by compositing with schisandra.

Operation steps of processing systems were disposed. A nine-step operation system was arranged for exploring the fermented compound dandelion wine. The series operation techniques included crushing, compositing, cooking, amylase saccharification, pectinase hydrolysis, inoculating, fermenting, filtering, blending, and other operations. In these techniques, cooking and enzymolysis were used to ferment dandelion wine at first time.

Fermented compound wine has enriched dandelion food and composited with schisandra to strengthen the function of this dandelion food.

Both dandelion and schisandra have the function of the protective effect on fatty liver $[14,15]$. This fermented wine composed dandelion and schisandra. Whether this compound wine have improved protective effect on fatty liver should be further tested by additional experiments.

\section{References}

1. Z. Kabir and R.T. Koide, Agriculture, Ecosystems and Environment, 78 (2000) 
2. L. H. Tahtamouni, N. M. Alqurna, M. Y. Al-Hudhud, H. A. Al-HajjSchütz, R. Carle and A. Schieber, Journal of Ethnopharmacology, 135 (2011)

3. B. Simandi, Sz.T. Kristo , A'. Kery, L.K. Selmeczi, I. Kmecz and S. Kemeny, Journal of Supercritical Fluids, 23 (2002)

4. E. Racz-Kotilla, G. Racz and A. Solomon, Planta Med. 26 (1974)

5. T. Kuusi, H. Pyysalo, K. Autio and Lebensm.-Wiss. Technol. 18 (1985)

6. H. B. Wang, International Journal of Biological Macromolecules, 68 (2014)

7. A. A. Astafieva, A. A. Enyenihi, E. A. Rogozhin, S. A. Kozlov, E. V. Grishin, T. I. Odintsova, R. A. Zubarev and T. A. Egorov, Plant Science, 238 (2015)

8. A. Belscak-Cvitanovic, A. Busic, L. Barisic, D. Vrsaljko, S. Karlovic, I. Spoljaric, A. Vojvodi, G. Mrsic and D. Komes, Food Hydrocolloids, 57 (2016)

9. K. Schütz, R. Carle, A. Schieber, Journal of Ethnopharmacology, 107 (2006)
10. S. M. Oh, H. R. Kim, Y. J. Park, Y. H. Lee and K. H. Chung, Chinese Journal of Natural Medicines, 13 (2015)

11. M. Davaatseren, H. J. Hur, H. J. Yang, J. T. Hwang, J. H. Park, H. J. Kim, M. J. Kim, D. Y. Kwon and M. J. Sun, Food and Chemical Toxicology, 58 (2013)

12. Y. S. Kumar, R. S. Prakasam and O. V. S. Reddy, International Journal of Food Science \& Technology, 1(2009)

13. G. Liu, K. Zong, L. Zhang, Y. Jin, W. Pan and X. Yang, Innovational Edition of Farm Products Processing, 12(2009)

14. M. Davaatseren, H. J. Hur, H. J. Yang, Jin-Taek Hwang, J. H. Park,Hyun-Jin Kim, M. J. Kim, D. Y. Kwon and M. J. Sung, Food and Chemical Toxicology, 58(2013)

15. H. J. Park, S. J. Lee, Y. Song, S. J. Jang, Y. G. Ko, S. M. Kang, B. Y. Chung, H. D. Kim, G. S. Kim, and J. H. Cho, Journal of Medicinal Food, (1)2014 